\title{
Thermal Conductivity of Nanoparticles Filled Polymers
}

\author{
Hassan Ebadi-Dehaghani and Monireh Nazempour \\ Shahreza Branch, Islamic Azad University \\ Iran
}

\section{Introduction}

Thermal conductivity of polymers is an important thermal property for both polymer applications and processing. Polymers typically have intrinsic thermal conductivity much lower than those for metals or ceramic materials, and therefore are good thermal insulators. Further enhancement of this thermal insulating quality can be achieved by foaming polymers. In other applications which require higher thermal conductivity, such as in electronic packaging and encapsulations, satellite devices, and in areas where good heat dissipation, low thermal expansion and light weight are needed, polymers reinforced with fillers, organic or inorganic, are becoming more and more common in producing advanced polymer composites for these applications (Hodgin \& Estes, 1999; Tavman, 2004; Lee \& Eun, 2004; Liu \& Mather, 2004; Ishida \& Heights, 1999; Frank \& Phillip, 2002; Hermansen, 2001; Ishida, 2000). Most polymeric materials are processed and fabricated at elevated temperatures, often above their melting temperatures. This process may be long and expensive because of the low thermal conductivity of polymers. Subsequently, the cooling process or annealing may also be controlled by heat transport properties of polymers, which eventually affect the physical properties of the materials. One example is crystalline polymers, for which the structural and morphological features may be significantly changed with the speed of cooling. Careful consideration in designing polymer processing is vital to achieve desired properties.

For one-dimensional and rectilinear heat flow, the steady-state heat transfer in polymeric materials can be described by the Fourier's law of heat conduction:

$$
q=-k \frac{d t}{d x}
$$

where $\mathrm{q}$ is the heat flux (i.e., the heat transfer rate per unit area normal to the direction of flow), $x$ is the thickness of the material, $\mathrm{dT} / \mathrm{dx}$ is the temperature gradient per unit length, and the proportionality constant $\mathrm{k}$ is known as the thermal conductivity. The units for thermal conductivity $\mathrm{k}$ are expressed as $\mathrm{W} /(\mathrm{m} \mathrm{K})$ in SI units, Btu in./ $\left(\mathrm{ft}^{2}{ }^{\circ}{ }^{\circ} \mathrm{F}\right)$ in English units, and $\mathrm{cal} /\left(\mathrm{cm} \mathrm{s}^{\circ} \mathrm{C}\right)$ in cgs units. The corresponding units for heat flux are expressed as $\mathrm{W} /\left(\mathrm{m}^{2}\right), \mathrm{Btu} /\left(\mathrm{ft}^{2} \mathrm{~h}\right)$, and $\mathrm{cal} /\left(\mathrm{cm}^{2} \mathrm{~s}\right)$, respectively.

Heat transfer involves the transport of energy from one place to another by energy carriers. In a gas phase, gas molecules carry energy either by random molecular motion (diffusion) or by 
an overall drift of the molecules in a certain direction (advection). In liquids, energy can be transported by diffusion and advection of molecules. In solids, phonons, electrons, or photons transport energy. Phonons, quantized modes of vibration occurring in a rigid crystal lattice, are the primary mechanism of heat conduction in most polymers since free movement of electrons is not possible (Majumdar, 1998). In view of theoretical prediction, the Debye equation is usually used to calculate the thermal conductivity of polymers (Han \& Fina, 2010).

$$
\lambda=\frac{C_{p} v l}{3}
$$

where $C_{p}$ is the specific heat capacity per unit volume; $v$ is the average phonon velocity; and $l$ is the phonon mean free path.

For amorphous polymers, $l$ is an extremely small constant (i.e. a few angstroms) due to phonon scattering from numerous defects, leading to a very low thermal conductivity of polymers (Agari et al., 1997). Table 1 displays the thermal conductivities of some polymers (T’Joen et al., 2009), (Hu et al., 2007) and (Speight, 2005).

\begin{tabular}{|l|c|}
\hline Material & $\begin{array}{c}\text { Thermal Conductivity at } 25^{\circ} \mathrm{C} \\
(\mathrm{W} / \mathrm{m} \mathrm{K})\end{array}$ \\
\hline Low density polyethylene (LDPE) & 0.30 \\
\hline High density polyethylene (HDPE) & 0.44 \\
\hline Polypropylene (PP) & 0.11 \\
\hline Polystyrene (PS) & 0.14 \\
\hline Polymethylmethacrylate (PMMA) & 0.21 \\
\hline Nylon-6 (PA6) & 0.25 \\
\hline Nylon-6.6 (PA66) & 0.26 \\
\hline Poly(ethylene terephthalate) (PET) & 0.15 \\
\hline Poly(butylene terephthalate) (PBT) & 0.29 \\
\hline Polycarbonate (PC) & 0.20 \\
\hline Poly(acrylonitrile-butadiene-styrene) & 0.33 \\
\hline copolymer (ABS) & 0.25 \\
\hline Polyetheretherketone (PEEK) & 0.30 \\
\hline Polyphenylene sulfide (PPS) & 0.22 \\
\hline Polysulfone (PSU) & 0.35 \\
\hline Polyphenylsulfone (PPSU) & 0.19 \\
\hline Polyvinyl chloride (PVC) & 0.19 \\
\hline Polyvinylidene difluoride (PVDF) & 0.27 \\
\hline Polytetrafluoroethylene (PTFE) & 0.34 \\
\hline Poly(ethylene vinyl acetate) (EVA) & 0.11 \\
\hline Polyimide, Thermoplastic (PI) & 0.25 \\
\hline Poly(dimethylsiloxane) (PDMS) & 0.19 \\
\hline Epoxy resin & \\
\hline
\end{tabular}

Table 1. Thermal conductivities of some polymers (T'Joen et al., 2009), (Hu et al., 2007) and (Speight, 2005). 


\section{Thermal conductivity - measurement and modeling}

\subsection{Methods for thermal conductivity measurements}

Several methods, as reviewed elsewhere (Tritt \& Weston, 2004) and (Rides et al., 2009), have been proposed and used for measurement of the thermal conductivity of polymers and composites. Classical steady-state methods measure the temperature difference across the specimens in response to an applied heating power, either as an absolute value or by comparison with a reference material put in series or in parallel to the sample to be measured. However, these methods are often time consuming and require relatively bulky specimens.

Several non steady-state methods have also been developed, including hot wire and hot plate methods, temperature wave method and laser flash techniques (Nunes dos Santos, 2007). Among these, laser-flash thermal diffusivity measurement is widely used, being a relatively fast method, using small specimens (Nunes dos Santos, 2007), (Nunes dos Santos, 2005) and (Gaal et al., 2004). In this method, the sample surface is irradiated with a very short laser pulse and the temperature rise is measured on the opposite side of the specimen, permitting calculation of the thermal diffusivity of the material, after proper mathematical elaboration. The thermal conductivity $\mathrm{k}$ is then calculated according to Eq. (3):

$$
k=a C_{p} \rho
$$

where $a, C_{p}$ and $\rho$ are the thermal diffusivity, heat capacity and density, respectively.

Differential scanning calorimetry (DSC) methods may also be used, applying an oscillary (Marcus \& Blaine, 1994) or step temperature profile (Merzlyakov \& Schick, 2001) and analyzing the dynamic response.

Significant experimental error may be involved in thermal conductivity measurements, due to difficulties in controlling the test conditions, such as the thermal contact resistance with the sample, leading to accuracy of thermal conductivity measurements typically in the range of $5-10 \%$. In indirect methods, such as those calculating the thermal conductivity from the thermal diffusivity, experimental errors on density and heat capacity values will also contribute to the experimental error in the thermal conductivity.

\subsection{Modeling of thermal conductivity in composites}

Several different models developed to predict the thermal conductivity of traditional polymer composites are reviewed elsewhere (Bigg, 1995), (Zhou et al., 2007), (Zeng et al., 2009) and (Wang et al., 2008). The fundamentals are recalled in this section.

The two basic models representing the upper bound and the lower bound for thermal conductivity of composites are the rule of mixture and the so-called series model, respectively. In the rule of mixture model, also referred to as the parallel model, each phase is assumed to contribute independently to the overall conductivity, proportionally to its volume fraction (Eq. (4)):

$$
\mathrm{k}_{\mathrm{c}}=\mathrm{k}_{\mathrm{p}} \Phi_{\mathrm{p}}+\mathrm{k}_{\mathrm{m}} \Phi_{\mathrm{m}}
$$


where $k_{c}, k_{p}, k_{m}$ are the thermal conductivity of the composite, particle, matrix, respectively, and $\Phi_{p}, \Phi_{m}$ volume fractions of particles and matrix, respectively. The parallel model maximizes the contribution of the conductive phase and implicitly assumes perfect contact between particles in a fully percolating network. This model has some relevance to the case of continuous fiber composites in the direction parallel to fibers, but generally results in very large overestimation for other types of composites.

On the other hand, the basic series model assumes no contact between particles and thus the contribution of particles is confined to the region of matrix embedding the particle. The conductivity of composites accordingly with the series model is predicted by Eq. (5):

$$
k_{c}=\frac{1}{\left(\phi_{m}+k_{m}\right)+\left(\phi_{p}+k_{p}\right)}
$$

Most of the experimental results were found to fall in between the two models. However, the lower bound model is usually closer to the experimental data compared to the rule of mixture (Ebadi-Dehaghani et al., 2011; Bigg, 1995), which brought to a number of different models derived from the basic series model, generally introducing some more complex weighted averages on thermal conductivities and volume fractions of particles and matrix. These so-called second-order models including equations by Hashin and Shtrikman, Hamilton and Crosser, Hatta and Taya, Agari, Cheng and Vachon as well as by Nielsen (Bigg, 1995), (Zhou et al., 2007) and (Okamoto \& Ishida 1999), appear to reasonably fit most of the experimental data for composites based on isotropic particles as well as short fibers and flakes with limited aspect ratio, up to loadings of about $30 \%$ in volume.

In the case of the geometric mean model, the effective thermal conductivity of the composite is given by:

$$
K_{c}=K_{m}^{\phi_{m}}+K_{f}^{\phi_{f}}
$$

Lewis and Nielsen modified the Halpin-Tsai equation (Nielsen et al., 1994) to include the effect of the shape of the particles and the orientation or type of packing for a two-phase system.

$$
K_{c}=K_{m}\left[\frac{1+A B \phi_{f}}{1-B \psi \phi_{f}}\right]
$$

Where

$$
B=\frac{\frac{K_{f}}{K_{m}}-1}{\frac{K_{f}}{K_{m}}-A} \psi=1+\left(\frac{1-\phi_{\max }}{\phi_{\max }{ }^{2}}\right) \phi_{f}
$$

The values of $\mathrm{A}$ and $\Phi_{\max }$ were given for many geometric shapes and orientations (Weidenfeller et al., 2004).

This model appears to reasonably fit most of the experimental data for composites based on isotropic particles as well as short fibers and flakes with limited aspect ratio, up to loading of about $30 \%$ in volume. For higher loadings, the Nielsen's model appear to best fit the rapid increase of thermal conductivity above $30 \mathrm{vol} . \%$, thanks for the introduction of the maximum packing factor into the fitting equation, despite the evaluation of maximum packing factor in 
real composites may present difficulties due to particle size distribution and particle dispersion in the matrix. However, the basic assumption of separated particles in the effective medium approach is not valid in principle for highly filled composites, where contacts are likely to occur, possibly leading to thermally conductive paths (Tavman, 1996).

Maxwell, using potential theory, obtained an exact solution for the conductivity of randomly distributed and non-interacting homogeneous spheres in a homogeneous medium:

$$
K_{c}=K_{m}\left[\frac{K_{f}+2 K_{m}+2 \phi_{f}\left(K_{f}-K_{m}\right)}{K_{f}+2 K_{m}-\phi_{f}\left(K_{f}-K_{m}\right)}\right]
$$

Other theoretical models have attempted to explain the thermal conductivity of two-phased composites. Some of these models, such as those by Bruggeman, Botcher, De Loor, and Ce Wen Nan et al., equations 6 to 9 respectively, have been used for prediction of thermal conductivity of carbon nanotube composites (Bruggeman, 1935; Böttcher, 1952; deLoor, 1956; Nan et al., 2004).

$$
\begin{gathered}
K_{c}=\frac{K_{m}}{\left(1-\phi_{f}\right)^{3}} \\
K_{c}=\frac{K_{m}}{\left(1-\phi_{f}\right)} \\
K_{c}=\frac{K_{m}\left(1+\phi_{f}\right)}{1-2 \phi_{f}} \\
K_{c}=\frac{K_{m}\left[3+\phi_{f}\left(\frac{K_{f}}{K_{m}}\right)\right]}{3-2 \phi_{f}}
\end{gathered}
$$

In order to take into account fluctuations in thermal conductivity in the composites, Zhi et al. (Zhi et al., 2009) proposed the concept of heat-transfer passages, to model the conduction in regions where interparticle distance is low, applying the series model to "packed-belt" of conductive particles.

Even though these macroscopic approaches may be of interest from the engineering point of view, they deliver little or no information about the physical background of the observed behavior. As an example, very limited interpretation is given to the rapidly increasing conductivity with filler content above a certain filler loading (typically above $30 \mathrm{vol} \%$ ), or why the experimental results are so far away from the upper bound conductivity, even for highly percolated systems.

Attempts to model thermal conductivity taking into account the interfacial thermal resistance between conductive particles and matrix have been reported by several research groups (Nan et al., 1997), (Every et al., 1992), (Dunn \& Taya, 1993), (Lipton \& Vernescu, 1996) and (Torquato \& Rintoul, 1995) and applied particles with different geometries and topologies, including aligned continuous fibers, laminated flat plates, spheres, as well as disoriented ellipsoidal particles. In general, these models provided an improved fit with experimental data for ceramic based composites than models not accounting for interface thermal resistance. These approaches generally assume conductive particles to be isolated in the matrix and take into account the thermal resistance in heat transfer between conductive 
particle and matrix, also known as Kapitza resistance, from the name of the discoverer of the temperature discontinuity at the metal-liquid interface. A very simple proof of thermal interfacial resistance is the fact that a thermal conductivity lower than the reference matrix was experimentally found with some composites containing particles with thermal conductivity higher than the matrix (Nan et al., 1997) and (Every et al., 1992). This phenomenon is explained by the very low efficiency of heat transfer between particles and matrix, so that the higher thermal conductivity of the filler cannot be taken into advantage and the composite behaves like a hollow material, thus reducing its conductivity compared to the dense reference matrix. Evaluation of the effective thermal conductivity of composite polymers by considering the filler size distribution law was investigated by Holotescu et al (Holotescu et al., 2009).

They presented an empirical model for the effective thermal conductivity (ETC) of a polymer composite that includes dependency on the filler size distribution-chosen as the Rosin-Rammler distribution. The ETC is determined based on certain hypotheses that connect the behavior of a real composite material A, to that of a model composite material B, filled with mono-dimensional filler. The application of these hypotheses to the Maxwell model for ETC is presented. The validation of the new model and its characteristic equation was carried out using experimental data from the reference. The comparison showed that by using the size distribution law a very good fit between the equation of the new model (the size distribution model for the ETC) and the reference experimental results is obtained, even for high volume fractions, up to about $50 \%$.

\section{Crystallinity and temperature dependence}

Polymer crystallinity strongly affects their thermal conductivity, which roughly varies from $0.2 \mathrm{~W} / \mathrm{m} \mathrm{K}$ for amorphous polymers such as polymethylmethacrylate (PMMA) or polystyrene (PS), to $0.5 \mathrm{~W} / \mathrm{m} \mathrm{K}$ for highly crystalline polymers as high-density polyethylene (HDPE) (Hu et al., 2007). The thermal conductivity of semi-crystalline polymers is reported to increase with crystallinity. As an example, the thermal conductivity of polytetrafluoroethylene (PTFE) was found to increase linearly with crystallinity at $232{ }^{\circ} \mathrm{C}$ (Price \& Jarratt, 2002).

However, there is a large scatter in the reported experimental data of thermal conductivity of crystalline polymers, even including some contradictory results. It should be noticed that the thermal conductivities of polymers depend on many factors, such as chemical constituents, bond strength, structure type, side group molecular weight, molecular density distribution, type and strength of defects or structural faults, size of intermediate range order, processing conditions and temperature. Furthermore, due to the phonon scattering at the interface between the amorphous and crystalline phase and complex factors on crystallinity of polymer, the prediction of the thermal conductivity vs. crystallinity presents a significant degree of complexity (Han \& Fina, 2010).

Semicrystalline and amorphous polymers also vary considerably in the temperature dependence of the thermal conductivity. At low temperature, semicrystalline polymers display a temperature dependence similar to that obtained from highly imperfect crystals, having a maximum in the temperature range near $100 \mathrm{~K}$, shifting to lower temperatures and higher thermal conductivities as the crystallinity increases (Greig \& Hardy, 1981) and (Yano 
\& Yamaoka, 1995), while amorphous polymers display temperature dependence similar to that obtained for inorganic glasses with no maximum, but a significant plateau region at low temperature range (Reese, 1969). The thermal conductivity of an amorphous polymer increases with increasing temperature to the glass transition temperature $\left(T_{g}\right)$, while it decreases above $T_{g}$ (Zhong et al., 2001) and (Dashora \& Gupta, 1996). The study of the thermal conductivity of some amorphous and partially crystalline polymers (PE, PS, PTFE and epoxy resin) as a function of temperature in a common-use range (273-373 K) indicates that the conductivity of amorphous polymers increases with temperature and that the conductivity is significantly higher in crystalline than amorphous regions (Kline, 1961).

From the general overview given in the preceding, it appears that very limited thermal conductivity is usually characteristic of polymers. On the other hand, there are many reasons to increase thermal conductivity of polymer-based materials in various industrial applications including circuit boards in power electronics, heat exchangers, electronics appliances and machinery. This justifies the recent significant research efforts on thermally conductive composite materials to overcome the limitations of traditional polymers.

\section{Fillers for thermally conductive composites}

Many applications would benefit from the use of polymers with enhanced thermal conductivity. For example, when used as heat sinks in electric or electronic systems, composites with a thermal conductivity approximately from 1 to $30 \mathrm{~W} / \mathrm{m} \mathrm{K}$ are required (King et al., 1999). The thermal conductivity of polymers has been traditionally enhanced by the addition of thermally conductive fillers, including graphite, carbon black, carbon fibers, ceramic or metal particles (see Table 2) (Pierson, 1993), (Wypych, 2000), (Fischer, 2006),

\begin{tabular}{|l|c|}
\hline Material & $\begin{array}{c}\text { Thermal Conductivity at } 25^{\circ} \mathbf{C} \\
\text { (W/m K) }\end{array}$ \\
\hline Graphite & 100 \\
\hline Carbon black & 2000 (on plane) \\
\hline Carbon Nanotubes & 2000 \\
\hline Diamond & 8000 \\
\hline PAN-based Carbon Fibre & (along the axis) \\
\hline Pitch-based Carbon Fibre & 483 \\
\hline Copper & 340 \\
\hline Silver & 204 \\
\hline Gold & 158 \\
\hline Aluminum & 250 \\
\hline Nickel & 200 \\
\hline Boron Nitride & 260 \\
\hline Aluminum nitride & $20 \% 29$ \\
\hline Beryllium oxide & (along the axis) \\
\hline Aluminum oxide & 200 \\
\hline
\end{tabular}

Table 2. Thermal conductivities of some thermally conductive fillers (Pierson, 1993), (Wypych, 2000), (Fischer, 2006), (Wolff \& Wang, 1993) and (Kelly, 1981). 
(Wolff \& Wang, 1993) and (Kelly, 1981). It is worth noticing that significant scatter of data are typically reported for thermal conductivity of fillers. This is caused by several factors, including filler purity, crystallinity, particle size and measurement method. It is also important to point out that some materials, typically fibers and layers, are highly anisotropic and can show much higher conductivity along a main axis or on a plane, compared to perpendicular direction.

High filler loadings ( $>30$ vol.\%) are typically necessary to achieve the appropriate level of thermal conductivity in thermally conductive polymer composites, which represents a significant processing challenge. Indeed, the processing requirements, such as possibility to be extruded and injection molded, often limit the amount of fillers in the formulation and, consequently, the thermal conductivity performance (King et al., 2008). Moreover, high inorganic filler loading dramatically alters the polymer mechanical behavior and density. For these reasons, obtaining composites having thermal conductivities higher than $4 \mathrm{~W} / \mathrm{m} \mathrm{K}$ and usual polymer processability is very challenging at present (Han \& Fina, 2010).

\subsection{Carbon-based fillers}

Carbon-based fillers appear to be the best promising fillers, coupling high thermal conductivity and lightweight. Graphite, carbon fiber and carbon black are well-known traditional carbon-based fillers. Graphite is usually recognized as the best conductive filler because of its good thermal conductivity, low cost and fair dispersability in polymer matrix (Causin et al., 2006) and (Tu \& Ye, 2009). Single graphene sheets constituting graphite show intrinsically high thermal conductivity of about $800 \mathrm{~W} / \mathrm{m} \mathrm{K}$ (Liu et al., 2008) or higher (theoretically estimated to be as high as $5300 \mathrm{~W} / \mathrm{m} \mathrm{K}$ ( Veca et al., 2009) and (Stankovich et al., 2006)), this determining the high thermal conductivity of graphite, usually reported in the range from 100 to $400 \mathrm{~W} / \mathrm{m} \mathrm{K}$. Expanded graphite (EG), an exfoliated form of graphite with layers of 20-100 $\mathrm{nm}$ thickness, has also been used in polymer composites (Ganguli et al., 2008), for which the thermal conductivity depends on the exfoliation degree (Park et al., 2008), its dispersion in matrix (Mu \& Feng, 2007) and the aspect ratio of the EG (Kalaitzidou et al., 2007).

Thermal conductivity of exfoliated graphite nanocomposites was investigated by Fukushima et al. (Fukushima et al., 2006). Since the late 1990's, research has been reported where intercalated, expanded, and/or exfoliated graphite nanoflakes could also be used as reinforcements in polymer systems. The key point to utilizing graphite as a platelet nanoreinforcement is in the ability to exfoliate graphite using Graphite Intercalated Compounds (GICs). Natural graphite is still abundant and its cost is quite low compared to the other nano-size carbon materials, the cost of producing graphite nanoplatelets is expected to be $\sim \$ 5 / \mathrm{lb}$. This is significantly less expensive than single wall nanotubes $(\mathrm{SWNT})(>\$ 45000 / \mathrm{lb})$ or vapor grown carbon fiber $(\mathrm{VGCF})(\$ 40-50 / \mathrm{lb})$, yet the mechanical, electrical, and thermal properties of crystalline graphite flakes are comparable to those of SWNT and VGCF. The use of exfoliated graphite flakes $(x \mathrm{GnP})$ opens up many new applications where electromagnetic shielding, high thermal conductivity, gas barrier resistance or low flammability are required. A special thermal treatment was developed to exfoliate graphite flakes for the production of nylon and high density polypropylene nanocomposites. X-ray diffraction (XRD), scanning electron microscopy (SEM) and transmission electron microscopy (TEM) were used to assess the degree of exfoliation of the 
graphite platelets and the morphology of the nanocomposites. The thermal conductivity of these composites was investigated by three different methods, namely, by DSC, modified hot wire, and halogen flash lamp methods. The addition of small amounts of exfoliated graphite flakes showed a marked improvement in thermal and electrical conductivity of the composites.

Carbon fiber, typically vapor grown carbon fiber (VGCF), is another important carbon-based filler. Polymer/VGCF composites have been reviewed by Tibbetts et al. (Tibbetts et al., 2007). Since VGCF is composed of an annular geometry parallel to the fiber axis, thermal conductive properties along the fiber axis are very different from the transverse direction (estimated up to $2000 \mathrm{~W} / \mathrm{m} \mathrm{K}$ in the axial direction vs. $10-110 \mathrm{~W} / \mathrm{m} \mathrm{K}$ in the transverse direction (Chen \& Ting, 2002) and (Zhang et al, 2000)), directly affecting the thermal conductivity of aligned composites (Mohammed \& Uttandaraman, 2009) and (Kuriger et al., 2002).

Carbon black particles are aggregates of graphite microcrystals and characteristic of their particle size $(10-500 \mathrm{~nm})$ and surface area $\left(25-150 \mathrm{~m}^{2} / \mathrm{g}\right.$ ) (Pierson, 1993). Carbon black is reported to contribute to electrical conductivity rather than thermal conductivity (Wong et al., 2001), (Abdel-Aal et al., 2008) and (King et al., 2006).

\subsection{Metallic fillers}

The filling of a polymer with metallic particles may result in both increase of thermal conductivity and electrical conductivity in the composites. However, a density increase is also obtained when adding significant metal loadings to the polymer matrix, thus limiting applications when lightweight is required. Metallic particles used for thermal conductivity improvement include powders of aluminum, silver, copper and nickel. Boudenne et al studied the thermal behavior of polypropylene filled with copper particles (Kumlutaş et al., 2003). In this work thermal conductivity, diffusivity, effusivity and specific heat of polypropylene matrix filled with copper particles of two different sizes were investigated. A parallel study of the evolution of the electrical conductivity was also carried out. The highest heat transport ability was observed for the composites filled with the smaller particles. The Agari's model provides a good estimation of the thermal conductivity of composites for all filler concentrations. Polymers modified with the inclusion of metallic particles include polyethylene (Kumlutaş et al., 2003), polypropylene (Boudenne et al., 2005), polyamide (Tekce et al., 2007), polyvinylchloride and epoxy resins (Mamunya et al., 2002), showing thermal conductivity performance depending on the thermal conductivity of the metallic fillers, the particle shape and size, the volume fraction and spatial arrangement in the polymer matrix. Thermal conductivity of metal powder-polymer feedstock for powder injection moulding was studied by Kowalski et al. (Kowalski et al., 1999).

Thermal conductivity of a powder injection molding feedstock (mixture of metal powders and polymers) in solid and molten states has been measured by using the laser flash method. The filler material was 316L stainless steel powder and its content in the mixture amounted $60 \%$ by volume. An attempt has been made to employ two most promising existing mathematical models (theoretical Maxwell- and semi-theoretical Lewis \& Nielsen model) to calculate the thermal conductivity of the mixture (see section 1.3.2). Comparison of the experimental and calculated results has revealed that the Lewis \& Nielsen model 
predicts better than Maxwell model the thermal conductivity of the feedstock. As the difference between the calculated (Maxwell model) and the measured results amounts to $15-85 \%$, it is suggested that it can only be used for preliminary assessment of the thermal conductivity of so highly filled composite material. If accurate thermal conductivity data are required (as in case of numerical simulation of the powder injection moulding process), measurement of this property has to be performed if meaningful simulation results are to be expected.

\subsection{Ceramic fillers}

Ceramic powder reinforced polymer materials have been used extensively as electronic materials. Being aware of the high electrical conductivity of metallic particles, several ceramic materials such as aluminum nitride (AIN), boron nitride (BN), silicon carbide ( $\mathrm{SiC})$ and beryllium oxide $(\mathrm{BeO})$ gained more attention as thermally conductive fillers due to their high thermal conductivity and electrical resistivity (Nu et al., 2008) and (Ishida \& Rimdusit, 1998). Thermal conductivities of composites with ceramic filler are influenced by filler packing density(Ohashi et al., 2005), particle size and size distribution (Yu et al., 2002) and (Mu et al., 2007), surface treatment (Gu et al., 2009) and mixing methods (Zhou et al., 2007). Models and theories for predicting the thermal conductivity of polymer composites were discussed. Effective Medium Theory (EMT), Agari model and Nielsen model respectively are introduced and are applied as predictions for the thermal conductivity of ceramic particle filled polymer composites. Thermal conductivity of experimentally prepared $\mathrm{Si}_{3} \mathrm{~N}_{4}$ /epoxy composite and some data cited from the literature are discussed using the above theories. Feasibility of the three methods as a prediction in the whole volume fraction region of the filler from 0 to 1 was evaluated for a comparison. As a conclusion: both EMT and Nielsen model can give a well prediction for the thermal conductivity at a low volume fraction of the filler; Agari model give a better prediction in the whole range, but with larger error percentage (He et al., 2007).

\section{Nanocomposites for thermal conductivity}

Polymer nanocomposites are commonly defined as the combination of a polymer matrix and additives that have at least one dimension in the nanometer range. The additives can be one-dimensional (examples include nanotubes and fibres), two-dimensional (which include layered minerals like clay), or three-dimensional (including spherical particles). Over the past decade, polymer nanocomposites have attracted considerable interests in both academia and industry, owing to their outstanding mechanical properties like elastic stiffness and strength with only a small amount of the nanoadditives. This is caused by the large surface area to volume ratio of nanoadditives when compared to the micro- and macro-additives. Other superior properties of polymer nano-composites include barrier resistance, flame retardancy, scratch/wear resistance, as well as optical, magnetic, thermal conductivity and electrical properties. Polymer based nanocomposites can be obtained by the addition of nanoscale particles which are classified into three categories depending on their dimensions: nanoparticles, nanotubes and nanolayers. The interest in using nanoscaled fillers in polymer matrices is the potential for unique properties deriving from the nanoscopic dimensions and inherent extreme aspect ratios of the nanofillers (Mai et al., 2006). Kumar et al. (Kumar et al., 2009) summarized six interrelated characteristics of 
nanocomposites over conventional micro-composites: (1) low-percolation threshold (about 0.1-2 vol.\%), (2) particle-particle correlation (orientation and position) arising at lowvolume fractions (less than 0.001), (3) large number density of particles per particle volume (106 to $10^{8}$ particles $\left./ \mu \mathrm{m}^{3}\right)$, (4) extensive interfacial area per volume of particles $\left(10^{3}\right.$ to $\left.10^{4} \mathrm{~m}^{2} / \mathrm{ml}\right),(5)$ short distances between particles (10-50 $\mathrm{nm}$ at 1-8 vol.\%) and (6) comparable size scales among the rigid nanoparticles inclusion, distance between particles, and the relaxation volume of polymer chains (Han \& Fina, 2010).

Different nanoparticles have been used to improve thermal conductivity of polymers. As a few examples, HDPE filled with 7 vol.\% nanometer size expanded graphite has a thermal conductivity of $1.59 \mathrm{~W} / \mathrm{m} \mathrm{K}$, twice that of microcomposites $(0.78 \mathrm{~W} / \mathrm{m} \mathrm{K})$ at the same volume content (Ye et al., 2006). Poly(vinyl butyral) (PVB), PS, PMMA and poly(ethylene vinyl alcohol) (PEVA) based nanocomposites with $24 \mathrm{wt}$.\% boron nitride nanotubes (BNNT) have thermal conductivities of 1.80, 3.61, 3.16 and $2.50 \mathrm{~W} / \mathrm{m} \mathrm{K}$, respectively (Zhi et al., 2009). Carbon nanofiber was also reported to improve the thermal conductivity of polymer composites (Sui et al., 2008) and (Elgafy \& Lafdi, 2005). However, the most widely used and studied nanoparticles for thermal conductivity are certainly carbon nanotubes (either single wall-SWCNT or multiwall-MWCNT), which have attracted growing research interest. Indeed, CNT couples very high thermal conductivity with outstanding aspect ratio, thus forming percolating network at very low loadings.

Droval and co-workers (Droval et al., 2006) investigated the effect of boron nitride (BN), talc $\left(\mathrm{Mg}_{3} \mathrm{Si}_{4} \mathrm{O}_{10}(\mathrm{OH})_{2}\right)$, aluminum nitride $(\mathrm{AlN})$ and aluminum oxide $\left(\mathrm{Al}_{2} \mathrm{O}_{3}\right)$ particles, and their impact on thermal properties. Lewis and Nielson, Cheng and Vachon, Agari and Uno models were used to predict the evolution of thermal conductivity with filler content and were found to describe correctly thermal conductivity. Only BN shows a real exponential increase of conductivity over $20 \% \mathrm{v} / \mathrm{v}$ filler. Consequently, in best conditions introducing $30 \% \mathrm{v} / \mathrm{v}$ of $\mathrm{BN}$ allows the thermal conductivity to be multiplied by six.

A technology has been developed for making carbon-ceramic composite refractories by combining carbon fibers as reinforcing component with a mixture matrix, which allows one to make refractory components of various sizes and geometry, including thin-walled large constructions (Chernenko et al., 2009). The heat resistance of these composite refractories increases with the bulk silicization during ceramic production on a carbon-carbon substrate. The degree of silicization is determined by the volume of the open microporosity of transport type, which is formed by pyrolysis of a polymer coke-forming matrix in the initial carbon plastic. The transport micropores are produced by a modification of the phenolformaldehyde resin additive treatment, which does not give rise to coke on pyrolysis. As a result, the content of open pores in the carbon framework attains $55 \%$, which enables one to make a silicized composite refractory of density up to $2.7 \mathrm{~g} / \mathrm{cm}^{3}$ with a compressive strength of $250-300 \mathrm{MPa}$, bending strength 120-140, and tensile strength $60-80 \mathrm{MPa}$, elastic modulus 120-140 GPa, linear expansion coefficient $3.5 \times 10^{-6}-4.5 \times 10^{-6} \mathrm{~K}^{-1}$, and thermal conductivity $6-8 \mathrm{~W} /(\mathrm{m} \mathrm{K})$. These refractories are widely used in various branches of industry. Thermal conductivity of particle filled polyethylene composite materials was investigated by Kumlutas et al. (Kumlutas et al., 2003). In this study, the effective thermal conductivity of aluminum filled high-density polyethylene composites is investigated numerically as a function of filler concentration. The obtained values are compared with experimental results and the existing theoretical and empirical models. The thermal 
conductivity is measured by a modified hot-wire technique. For numerical study, the effective thermal conductivity of particle-filled composite was calculated numerically using the micro structural images of them. By identifying each pixel with a finite difference equation and accompanying appropriate image processing, the effective thermal conductivity of composite material is determined numerically. As a result of this study, numerical results, experimental values and all the models are close to each other at low particle content. For particle content greater than $10 \%$, the effective thermal conductivity is exponentially formed. All the models fail to predict thermal conductivity in this region. But, numerical results give satisfactory values in the whole range of aluminum particle content.

\subsection{Nanocomposites using inorganic fillers}

Thermally conductive polymer nanocomposites based on polypropylene has been studied (Vakili et al., 2011; Ebadi-Dehaghani et al., 2011). In this study three nanocomposite containing 5 to $15 \mathrm{wt} \%$ of $\mathrm{ZnO}$ and $\mathrm{CaCO} 3$ nanoparticles prepared by extrusion were used. The thermal conductivity (TC) of compression moulded polypropylene (PP) and PP filled nanoparticles was studied using thermal conductivity analyser (TCA). The effect of nanoparticle content and crystallinity on thermal conductivity was investigated using conventional methods like SEM, XRD and DSC. The incorporation of nanoparticles improved crystallinity and thermal conductivity simultaneously. The experimental TC values of PP nanocomposites with different level of nanoparticles concentration showed a linear increase with an increase in crystallinity.

\subsubsection{Differential Scanning Calorimetry (DSC)}

DSC measurements were investigated by conventional differential scanning calorimeter Labsys TG (Setaram Instumentation, Caluire, France). A pellet of extruded sample, with a weight of 8-10 mg, was placed into an alumina pan in the presence of air as the furnace atmosphere. Measurements were performed from ambient temperature up to $200^{\circ} \mathrm{C}$ with heating rate of $10^{\circ} \mathrm{C} / \mathrm{min}$. The DSC results for pure PP and nanocomposites, The Tm (peak temperature of melting) and $\Delta \mathrm{Hm}$ (enthalpy of melting), are listed in Table 3.

The degree of crystallinity of a specimen can be calculated from the melting heat of crystallization according to the following equation:

$$
X_{\mathrm{c}}=\frac{\Delta H_{\mathrm{m}}}{\Delta H_{0}\left(1-W_{\mathrm{f}}\right)} \times 100
$$

Where $\mathrm{w}_{\mathrm{f}}$ is the weight fraction of nanofiller and $\Delta \mathrm{H}_{0}=207.1 \mathrm{Jg}^{-1}$ is the melting heat of $100 \%$ crystalline PP (Bai et al., 1999).

The DSC results indicated that the addition of both nanoparticles to the PP caused only a marginal effect on melting temperature $\left(\mathrm{T}_{\mathrm{m}}\right)$ and no correlation of the results with the filler concentration could be established. The calculated degree of crystallinity of the PP phase increased with increasing content of both nanoparticles, indicating that the nanofillers nucleated the crystallization process. (Frormann et al., 2008) This implies that the existence of nanoparticles facilitates the crystallization of PP and this effect becomes more evident with higher nanoparticle content (Zhao \& Li, 2006). Similar results for $\mathrm{PP} / \mathrm{CaCO} 3$ 
nanocomposites, $\mathrm{PP} /$ carbon nanotube composites and $\mathrm{PP} /$ nanoclay composites (Han \& Fina , 2011; Frormann et al., 2008; Vakili et al., 2011) have been reported. However there are some contradicting results in the literature (Zhao \& Li, 2006).

\begin{tabular}{lcccc}
\hline Neat PP & $\begin{array}{c}\text { PP+5wt\% } \\
\text { nanofiller }\end{array}$ & $\begin{array}{c}\text { PP+10wt\% } \\
\text { nanofiller }\end{array}$ & $\begin{array}{c}\text { PP+15wt\% } \\
\text { nanofiller }\end{array}$ \\
\hline $\mathrm{T}_{\mathrm{m}}\left({ }^{\circ} \mathrm{C}\right)$ & 167.8 & 168.5 & 168.8 & 167.0 \\
$\Delta \mathrm{H}_{\mathrm{m}}\left(\mathrm{Jg}^{-1}\right)$ & 78.0 & 91.2 & 108.9 & 107.7 \\
$\mathrm{X}_{\mathrm{c}}(\%)$ & 37.7 & 44.0 & 52.6 & 52.0
\end{tabular}

a)

\begin{tabular}{lcccc}
\hline Neat PP & $\begin{array}{c}\text { PP+5wt\% } \\
\text { nanofiller }\end{array}$ & $\begin{array}{c}\text { PP+10wt\% } \\
\text { nanofiller }\end{array}$ & $\begin{array}{c}\text { PP+15wt\% } \\
\text { nanofiller }\end{array}$ \\
\hline $\mathrm{T}_{\mathrm{m}}\left({ }^{\circ} \mathrm{C}\right)$ & 167.8 & 168.6 & 168.1 & 168.4 \\
$\Delta \mathrm{H}_{\mathrm{m}}\left(\mathrm{Jg}^{-1}\right)$ & 78.0 & 81.4 & 85.8 & 104.6 \\
$\mathrm{X}_{\mathrm{c}}(\%)$ & 37.7 & 39.3 & 41.4 & 50.5
\end{tabular}

b)

Table 3. Crystallization parameters of neat $\mathrm{PP}$ and nanocomposites. a) $\mathrm{PP} / \mathrm{ZnO}$ nanocomposite. b) $\mathrm{PP} / \mathrm{CaCO}_{3}$ nanocomposite.

\subsubsection{Thermal conductivity measurement}

Thermal conductivity was measured using a TCA Thermal Conductivity Analyser (TCA200LT-A, Netzsch, Selb, Germany) with the guarded heat flow meter method. Each compression molded sample $(30 \mathrm{~cm} \times 30 \mathrm{~cm}$ sheets with $10 \mathrm{~mm}$ thickness $)$ was placed between two heated surface controlled at different temperatures with a flow of heat from the hot to the cold surface. When thermal equilibrium was attained thermal conductivity data were taken within an accuracy of $3 \%$. Fig. 1 compares the effect of the nanoparticles' content on the thermal conductivity of the nanocomposites. As seen, the value of thermal conductivity increased with an increase in the nanoparticle concentration up to $64 \%$ and $82 \%$ for $\mathrm{CaCO}_{3}$ and $\mathrm{ZnO}$ respectively. The increase in $\mathrm{TC}$ for $\mathrm{ZnO}$ nanoparticles is more than $\mathrm{CaCO}_{3}$ due to the nature of nanofiller and also crystallinity degree regarding to DSC results (Table 3). These increases in TC for both nanoparticles are higher than that of reported values for $\mathrm{CNF}$ in a PP matrix (Frormann et al., 2008).

The values obtained from the experimental study of PP nanocomposites were compared with several TC models (Figs 2.a and 2.b). As seen the experimental results were found to fall in between the Series and Parallel models. However, the lower bound model (series) is usually closer to the experimental data.

Maxwell, Lewis \& Nielson, Bruggeman, Bottcher and De Loor models predict fairly well thermal conductivity values up to $10 \mathrm{wt} \%$ for $\mathrm{PP} / \mathrm{ZnO}$ nanocomposites (Fig. 2.a). In the concentration of $15 \mathrm{wt} \%$ no model could predict well the TC values and all of the mentioned models underestimated the TC values of nanocomposite whereas in the case $5 \mathrm{wt} \%$ all models overestimated the TC values. 


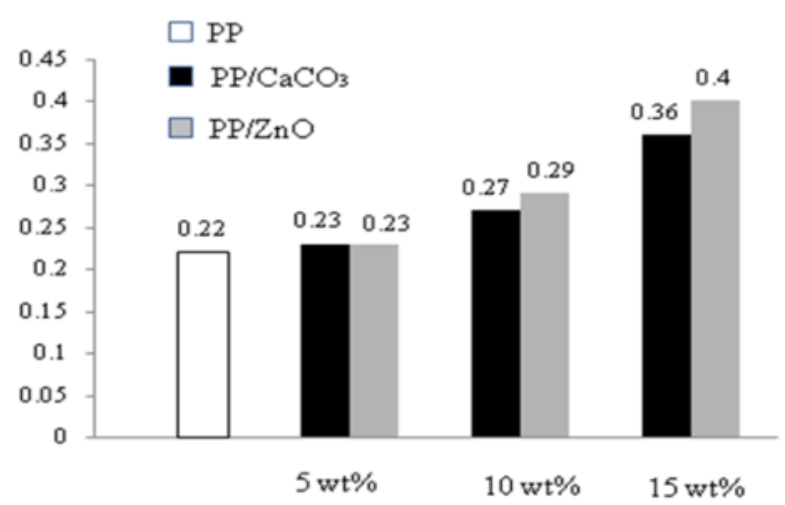

Fig. 1. Comparing the effect of nanoparticles on the TC of PP.

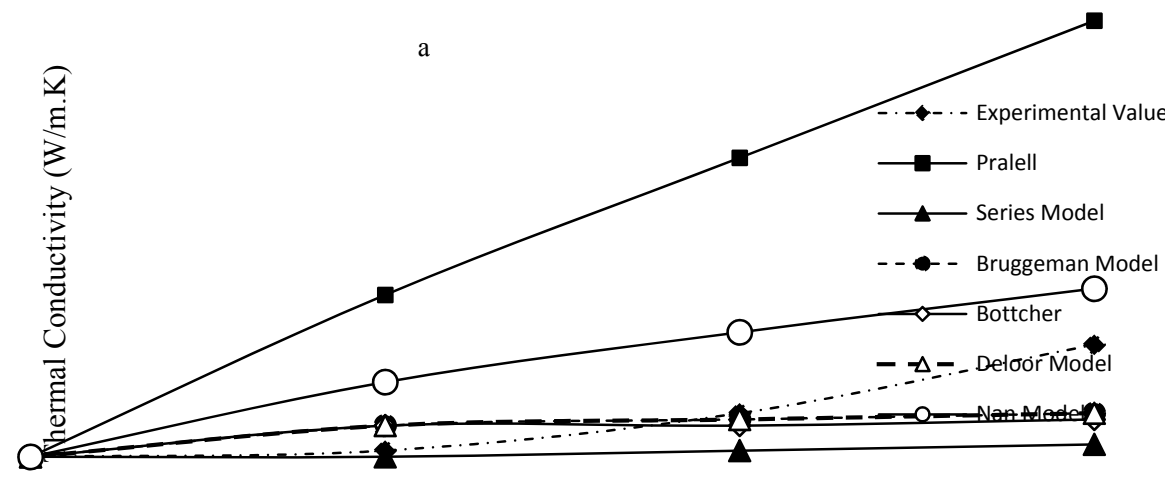

$w t \%$ of Nanofiller

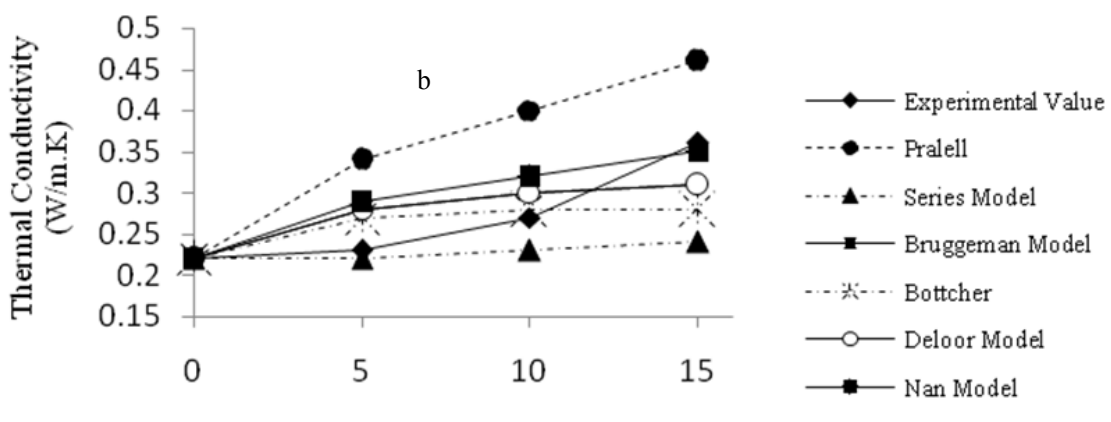

wt $\%$ of Nanofiller

Fig. 2. Comparing the experimental TC values vs nanoparticle content with theoretical models. a) $\mathrm{PP} / \mathrm{ZnO}$ nanocomposite b) $\mathrm{PP} / \mathrm{CaCO}_{3}$ nanocomposite. 
This fact can be attributed to the intrinsic thermal conductivity of both nanoparticles and their large surface area which even at lower loadings of nanofillers they are still effective to transfer heat through the samples (Frormann et al., 2008). At a higher volume fraction, this effect becomes stronger. Fig. 2.b the values obtained from the experimental study for $\mathrm{PP} / \mathrm{CaCO}_{3}$ nanocomposites are compared with a number of TC models. As seen the Ce Wen Nan model predicts fairly well the thermal conductivity values up to $15 \mathrm{wt} \%$. For the concentration of $10 \mathrm{wt} \%$ all the models predict the TC values well. In the case of $15 \mathrm{wt} \%$ other models underestimated the TC values of nanocomposites except for the Ce Wen Nan model, whereas for $5 \mathrm{wt} \%$ all models overestimated the TC value. The predicted TC values by the models depend on the nature of nanofiller and their relative concentrations (Weidenfeller et al., 2004; Frormann et al., 2008).

The TC improvement in $\mathrm{PP} / \mathrm{ZnO}$ nanocomposite is greater than that of $\mathrm{PP} /$ calcium carbonate nanocomposites. This fact can be attributed to intrinsic thermal conductivity of the $\mathrm{ZnO}$ nanoparticles. Several models have been used for prediction of TC in the nanocomposites (see section 3.2). In the $\mathrm{PP} / \mathrm{ZnO}$ nanocomposites TC values correlated well with the values predicted by Series, Maxwell, Lewis \& Nielson, Bruggeman and De Loor models up to $10 \mathrm{wt} \%$.

\section{Conclusions}

As electronic devices tend to become slimmer and more integrated, heat management become a central task for device design and application. Similar issues are faced in several other applications, including electric motors and generators, heat exchangers in power generation, automotive, etc. Metallic materials are widely used as heat dissipation materials, but there have been many attempts to replace the metallic materials with highly thermally conductive polymer based composites due to their lightweight, corrosion resistance, easy processing and lower manufacturing cost.

Thermally conductive polymer based composites are tentatively prepared by the incorporation of thermally conductive fillers. The outstanding thermal conductivity of mentioned fillers makes them a promising candidates to obtain highly thermally conductive polymer based composites.

PP nanocomposites were prepared by melt extrusion in a twin screw extruder. The introduction of nanoparticles resulted in an increase in crystallinity. Scanning electron microscopy (SEM) indicated a good dispersion of the nanofillers within the PP matrix that might enhance the thermal conductivity of the nanocomposites even at lower nanofiller loadings owing to enhanced filler-matrix interaction. The thermal conductivity of $\mathrm{PP} / \mathrm{ZnO}$ nanocomposites had an increase of $82 \%$ at $15 \mathrm{wt} \%$ concentration comparing to that of pure $\mathrm{PP}$, while for $\mathrm{PP} / \mathrm{CaCO}_{3}$ nanocomposite with same level of nanoparticle content it was $64 \%$, so it is concluded that $\mathrm{ZnO}$ nanoparticles had more intrinsic potential to improve thermal conductivity of $\mathrm{PP}$ comparing to $\mathrm{CaCO}_{3}$ nanoparticles regarding to its nature and crystallinity.

The thermal conductivity was increased from $\mathrm{K}=0.22 \mathrm{~W} / \mathrm{mK}$ for pure PP by $64 \%$ for the sample with $15 \mathrm{wt} \%$ of $\mathrm{CaCO}_{3}$ nanoparticles. These results for both nanocomposites $\left(\mathrm{PP} / \mathrm{ZnO}\right.$ and $\mathrm{PP} / \mathrm{CaCO}_{3}$ ) are higher than the values which reported for $\mathrm{CNF}$ in a PP matrix 
Frormann L, Iqbal A, Abdullah S.A. 2008. The measured values were also compared with various models in the investigated range of nanofiller concentration. The Series, Maxwell, Lewis \& Nielson, Bruggeman, Bottcher, De Loor and Ce Wen Nan models predicted fairly well the thermal conductivity values for the samples containing more than $5 \mathrm{wt} \%$ of nanoparticles. The experimental TC values of PP nanocomposites showed a linear increase with an increase in concentration and crystallinity.

\section{Abbreviations}

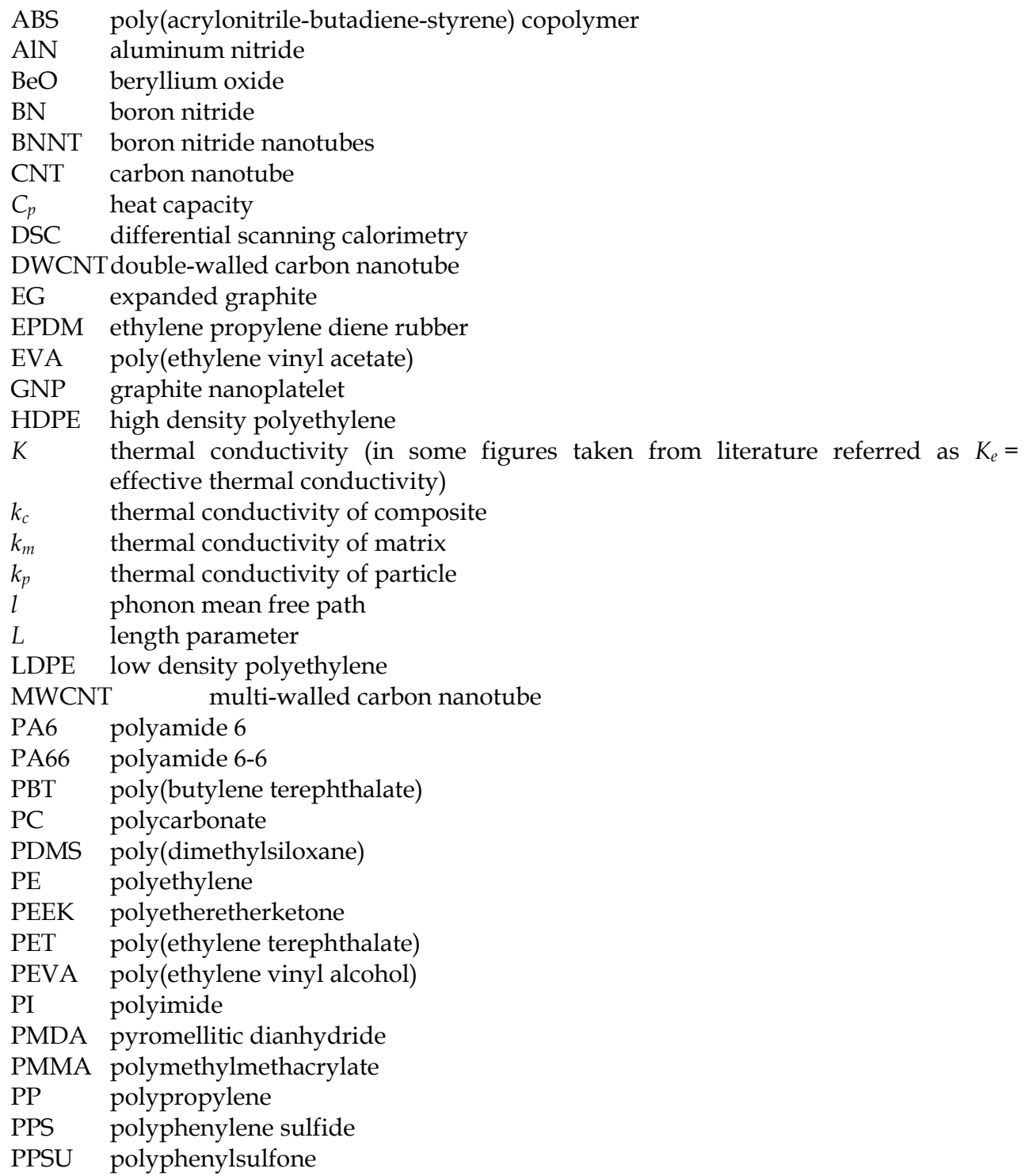




$\begin{array}{ll}\text { PS } & \text { polystyrene } \\ \text { PSU } & \text { polysulfone } \\ \text { PTFE } & \text { polytetrafluoroethylene } \\ \text { PU } & \text { polyurethane } \\ \text { PVB } & \text { poly(vinyl butyral) } \\ \text { PVC } & \text { polyvinyl chloride } \\ \text { PVDF } & \text { polyvinylidene difluoride } \\ R_{k} & \text { interfacial resistance } \\ \text { SiC } & \text { silicon carbide } \\ \text { SWCNT } & \text { single-walled carbon nanotube } \\ T_{g} & \text { glass transition temperature } \\ v & \text { average phonon velocity } \\ \text { VGCF } & \text { vapor grown carbon fiber } \\ A & \text { thermal diffusivity } \\ \rho & \text { density of the material } \\ \Phi_{m} & \text { volume fractions of matrix } \\ \Phi_{p} & \text { volume fractions of particles } \\ \mathrm{W}_{\mathrm{f}} & \text { weight fraction of particles } \\ & \end{array}$

\section{References}

Abdel-Aal N.; El-Tantawy F.; Al-Hajry A. \& Bououdina M. (2008), Epoxy resin/plasticized carbon black composites. Part I. Electrical and thermal properties and their applications, Polymer Composites, vol.29 pp. 511-517.

Agari Y., Ueda A., Omura Y. \& Nagai S. (1997), Thermal diffusivity and conductivity of PMMA-PC blends, Polymer, vol.38, pp. 801-807.

Bai F.; Li F.; Calhoun B.; Quirk R.P. \& Cheng S.Z.D. (1999), Polymer Handbook, 4th edition. In: John Wiley ESons, Inc., New York.

Bigg D.M. (1995), Thermal conductivity of heterophase polymer compositions, Advanced Polymer Science, vol.119, pp. 1-30.

Böttcher C. (1952), Theory of Electric Polarization, In: Elsevier. Amsterdam, Netherlands.

Boudenne A.; Ibos L.; Fois M.; Majeste J.C. \& Géhin E. (2005), Electrical and thermal behavior of polypropylene filled with copper particles, Composites: part A, vol.36, pp. 1545-1554.

Bruggeman D. (1935), Dielectric constant and conductivity of mixtures of isotropic materials. Annual Physics, vol.24, pp. 636-645.

Causin V.; C. Marega;A. Marigo; G. Ferrara \& A. Ferraro (2006), Morphological and structural characterization of polypropylene/conductive graphite nanocomposites, European Polymer Journal, vol.42, pp. 3153-3161.

Chen Y. \& Ting J. (2002), Ultra high thermal conductivity polymer composites, Carbon, vol.40, pp. 359-362.

Chernenko N. M.; Yu. N.; Beilina A. \& Sokolov I. (2009), TECHNOLOGICAL ASPECTS OF HEAT RESISTANCE IN CARBON-CERAMIC COMPOSITE REFRACTORIES. Refractories and Industrial Ceramics, Vol. 50, No. 2.

Dashora P. \& Gupta G. (1996), On the temperature dependence of the thermal conductivity of linear amorphous polymers, Polymer, vol.37, pp. 231-234. 
DeLoor G. (1956), Dielectric Proberties of heterogeneous mixtures. PhD Thesis, University of Leiden, NL. Leiden.

Droval G.; Feller J.F., Salagnac P. \& Glouannec P. (2006), Thermal conductivity enhancement of electrically insulating syndiotactic poly(styrene) matrix for diphasic conductive polymer composites. Polymers for Advanced Technology, vol.17, pp.732-745.

Dunn M.L. \& Taya M. (1993), The effective thermal conductivity of composites with coated reinforcement and the application to imperfect interfaces, Journal of Applied Physics. Vol.73, pp. 1711-1722.

Elgafy A. \& Lafdi K. (2005), Effect of carbon nanofiber additives on thermal behavior of phase change materials, Carbon, vol. 43, pp. 3067-3074.

Every A.G.; Tzou Y.; Hasselman D.P.H. \& Ray R. (1992), The effect of particle size on the thermal conductivity of $\mathrm{ZnS} /$ diamond composites, Acta Metallurgica et Materialia, vol.40, pp. 123-129.

Ebadi-Dehaghani H.; Reiszadeh M.; Chavoshi A. \& Nazempour M. (2011), A study on the effect of zinc oxide $(\mathrm{ZnO})$ and calcium carbonate $\left(\mathrm{CaCO}_{3}\right)$ nanoparticles on the thermal conductivity (TC) of polypropylene. Composites: part B (revised)

Fischer J.E. (2006), Carbon nanotubes: structure and properties. Gogotsi Y., Carbon nanomaterials, Taylor and Francis Group, New York, pp. 51-58.

Frank H. R. \& Phillip D. S. (2002), Enhanced Boron Nitride Composition and Polymer Based High Thermal Conductivity Molding Compound, EP 0794227 B1.

Frormann L.; Iqbal A. \& Abdullah S.A. (2008), Thermo-viscoelastic behavior of PCNF-filled polypropylene nanocomposites. Journal of Applied Polymer Science; 107: 2695-2703.

Fukushima H.; Drzal L. T.; Rook B. P. \& Rich M. J. (2006), Thermal conductivity of exfoliated Graphite nanocomposites. Journal of Thermal Analysis and Calorimetry, Vol. 85, pp.235-238.

Gaal P.S.; Thermitus M.A. \& Stroe D.E. (2004), Thermal conductivity measurements using the flash method, Journal of Thermal Analysis and Calorimetry, vol.78, pp. 185-189.

Ganguli S.; Roy A.K. \& Anderson D.P. (2008), Improved thermal conductivity for chemically functionalized exfoliated graphite/epoxy composites, Carbon, vol.46, pp. 806-817.

Greig D. \& Hardy N.D. (1981), The thermal conductivity of semicrystalline polymers at very low temperatures, Journal of Physics Colloq, vol.42, pp. 69-71.

Gu J.; Zhang Q.; Dang J.; Zhang J. \& Yang Z. (2009), Thermal conductivity and mechanical properties of aluminum nitride filled linear low-density polyethylene composites, Polymer Engineering Science, vol.49, pp. 1030-1034.

Han Z. \& Fina A. (2011). Thermal conductivity of carbon nanotubes and their polymer nanocomposites: A review, Progress in Polymer Science, vol.36, Issue 7, pp.914-944.

He H.; Fu R.; Han Y.; Shen Y. \& Song X (2007), Thermal conductivity of ceramic particle filled polymer composites and theoretical predictions. Journal of Material Science, vol.42, pp.6749-6754. DOI 10.1007/s10853-006-1480-y.

Hermansen R. D. (2001), Room-Temperature Stable, One-Component, ThermallyConductive, Flexible Epoxy Adhesives, EP 0754741 B1.

Hodgin M. J. \& Estes R. H. (1999). Proceedings of the Technical Programs, NEPCO WEST Conference, pp. 359-366.Anaheim, CA.

Holotescu S. \& Stoian F. D. (2009), Evaluation of the effective thermal conductivity of composite polymers by considering the filler size distribution law. Journal of Zhejiang University SCIENCE A. vol. 10(5) pp.704-709. 
$\mathrm{Hu}$ M.; Yu D. \& Wei J. (2007), Thermal conductivity determination of small polymer samples by differential scanning calorimetry. Polymer Testing, vol.26, pp.333-337.

Ishida H. (2000), Surface Treated Boron Nitride for Forming A Low Viscosity High Thermal Conductivity Polymer Based on Boron Nitride Composition and Method, US Patent, 6,160,042.

Ishida H. \& Heights S. (1999), Composition for Forming High Thermal Conductivity Polybenzoxazine-Based Material and Method, US Patent 5,900,447.

Ishida H. \& Rimdusit S. (1998), Very high thermal conductivity obtained by boron nitridefilled polybenzoxazine, Thermochimica Acta, vol.320, pp. 177-186.

Kalaitzidou K.; Fukushima H. \& Drzal L.T. (2007), Multifunctional polypropylene composites produced by incorporation of exfoliated graphite nanoplatelets, Carbon, vol.45, pp. 1446-1452.

Kelly B.T. (1981), Physics of graphite, Applied Science Publishers, Barking (UK).

King J.A.; Barton R.L., Hauser R.A. \& Keith J.M. (2008), Synergistic effects of carbon fillers in electrically and thermally conductive liquid crystal polymer based resins, Polymer Composites, vol.29, pp. 421-428.

King J.A.; Morrison F.A.; Keith J.M.; Miller M.G.; Smith R.C.; Cruz M.; Neuhalfen A.M. \& Barton R.L. (2006), Electrical conductivity and rheology of carbon-filled liquid crystal polymer composites, Journal of Applied Polymer Science, vol.101, pp. 26802688.

King J.A.; Tucker K.W.; Vogt B.D.; Weber E.H. \& Quan C. (1999), Electrically and thermally conductive nylon 6,6, Polymer Composites, vol.20, pp. 643-654.

Kline D.E. (1961), Thermal conductivity studies of polymers, Journal of Polymer Science, vol.50, pp. 441-450.

Kowalski L.; Duszczyk J. \& Katgerman L(1999), Thermal conductivity of metal powderpolymer feedstock for powder injection moulding. Journal of Material Science, vol.34, pp.1- 5.

Kumar A.P.; Depan D.; Tomer N.S. \& Singh R.P. (2009), Nanoscale particles for polymer degradation and stabilization-trends and future perspectives, Progress Polymer Science, vol.34, pp. 479-515.

Kumlutas D.; Tavman I. H. \& Coban M.T. (2003). Thermal conductivity of particle filled polyethylene composite materials. Composites Science and Technology, vol.63, pp.113117.

Kuriger R.J.; Alam M.K.; Anderson D.P. \& Jacobsen R.L. (2002), Processing and characterization of aligned vapor grown carbon fiber reinforced polypropylene, Composites: PartA, vol.33, pp. 53-62.

Lee H. \& Eun S. (2004). In Composites 2004 Convention and Trade Show, American Composites Manufacturers Association, Tampa, Florida.

Lipton R. \& Vernescu B. (1996), Composites with imperfect interface, Proc $R$ Soc Lond A, vol.452, pp. 329-358.

Liu C. \& Mather T. (2004), ANTEC 2004, Society of Plastic Engineers, pp. 3080-3084.

Liu Z., Guo Q., Shi J., Zhai G. \& Liu L. (2008), Graphite blocks with high thermal conductivity derived from natural graphite flake, Carbon, vol.46, pp. 414-421.

Mai Y. \& Yu Z. (2006), Polymer nanocomposites. Woodhead publishing limited, Cambridge England. 
Majumdar A. (1998), Microscale transport phenomena. Rohsenow W.M.; Hartnett J.R. \& Cho Y.I., Handbook of heat transfer, (3rd ed.), McGraw-Hill, New York, pp. 8.1-8.8.

Mamunya Y.P.; Davydenko V.V.; Pissis P. \& Lebedev E.V. (2002), Electrical and thermal conductivity of polymers filled with metal powders, European Polymer Journal, vol.38, pp. 1887-1897.

Marcus S.M. \& Blaine R.L. (1994), Thermal conductivity of polymers, glasses and ceramics by modulated DSC, Thermochimica Acta, vol.243, pp. 231-239.

Merzlyakov M. \& Schick C. (2001), Thermal conductivity from dynamical response of DSC, Thermochimica Acta, vol.377, pp. 183-191.

Mohammed H.A. \& Uttandaraman S. (2009), A review of vapor grown carbon nanofiber/polymer conductive composites, Carbon, vol.47, pp. 2-22.

Momentive Performance Materials, Boron nitride finds new applications in thermoplastic compounds. (2008), Plastics, Additives and Compounding, (May/June), pp. 26-31.

Mu Q.; Feng S. \& Diao G. (2007), Thermal conductivity of silicone rubber filled with ZnO, Polymer Composites, vol.28, pp. 125-130.

Mu Q. and Feng S. (2007), Thermal conductivity of graphite/silicone rubber prepared by solution intercalation, Thermochimica Acta, vol.462, pp. 70-75.

Nan C.W.; Birringer R.; Clarke D.R. \& Gleiter H. (1997), Effective thermal conductivity of particulate composites with interfacial thermal resistance, Journal of Applied Physics, vol. 10, pp. 6692-6699.

Nan C.W.; Liu G.; Lin Y. \& Li M. (2004), Interface effect on thermal conductivity of carbon nanotube composites. Applied Physics Letter, vol. 85, pp.3549-3555.

Nielsen E.; Landel R.F. (1994), Mechanical Properties of Polymers and Composites. 2nd edition, Marcel Dekker Inc., New York.

Nunes dos Santos W., Mummery P. \& Wallwork A. (2005), Thermal diffusivity of polymers by the laser flash technique, Polymer Testing, vol.24, pp. 628-634.

Nunes dos Santos W. (2007), Thermal properties of polymers by non-steady-state techniques, Polymer Testing, vol.26, pp. 556-566.

Ohashi M.; Kawakami S. \& Yokogawa Y. (2005), Spherical aluminum nitride fillers for heatconducting plastic packages, Journal of American Ceramic Society, vol.88, pp. 26152618 .

Okamoto S. \& Ishida H. (1999), A new theoretical equation for thermal conductivity of twophase systems, Journal of Applied Polymer Science, vol.72, pp. 1689-1697.

Park S.H.; Hong C.M.; Kim S. \& Lee Y.J. (2008), Effect of fillers shape factor on the performance of thermally conductive polymer composites, ANTEC Plastics - Annual Technical Conference Proceedings 2008, pp. 39-43.

Price D.M. \& Jarratt M. (2002), Thermal conductivity of PTFE and PTFE composites, Thermochimiuca Acta, vol.392-393, pp. 231-236.

Pierson H.O. (1993), Handbook of carbon, graphite, diamond and fullerenes: properties. Processing and applications, Noyes Publications, New Jersey.

Reese W. (1969), Thermal properties of polymers at low temperatures, Journal of Macromolecular Science A, vol.3, pp. 1257-1295.

Rides M.; Morikawa J.; Halldahl L.; Hay B.; Lobo H.; Dawson A. \& Allen C. (2009), Intercomparison of thermal conductivity and thermal diffusivity methods for plastics, Polymer Testing, vol.28, pp. 480-489. 
Speight J.G. (2005), Lange's handbook of chemistry (16th ed.), McGraw-Hill, New York pp. 2794-2797.

Stankovich S.; Dikin D.A.; Dommett G.H.B.; Kohlhaas K.M.; Zimney E.J.; Stach E.A.; Piner R.D.; Nguyen S.T. \& Ruoff R.S., Graphene-based composite materials, Nature, vol.442 (2006), pp. 282-286.

Sui G.; Jana S.; Zhong W.H.; Fuqua M.A. \& Ulven C.A. (2008), Dielectric properties and conductivity of carbon nanofiber/semi-crystalline polymer composites, Acta Material, vol.56, pp. 2381-2388.

Tavman I.H. (1996), Thermal and mechanical properties of aluminum powder-filled highdensity polyethylene composites, Journal of Applied Polymer Science, vol. 62, pp. 2161-2167.

Tavman I. H. (2004). in Nanoengineered Nanofibrous Materials, NATO Science Series II, Mathematics, Physics and Chemistry, Guceri S. I.; Gogotsi Y. \& Kuzentsov V., Kluwer Academic Book Publication, Dordrecht, Netherlands, Vol. 169, p. 449.

Tekce H.S.; Kumlutas D. \& Tavman I.H. (2007), Effect of particle shape on thermal conductivity of copper reinforced polymer composites, Journal of Reinforced Plastics and Composites, vol.26. pp. 113-121.

Thostenson E.K.; Li C. \& Chou T.W. (2005), Nanocomposites in context, Composite Science Technology, vol.65, pp. 491-516.

Tibbetts G.G.; Lake M.L.; Strong K.L. \& Rice B.P. (2007), A review of the fabrication and properties of vapor-grown carbon nanofiber/polymer composites, Composite Science Technology, vol.67, pp. 1709-1718.

T'Joen C.; Park Y.; Wang Q.; Sommers A.; Han X. \& Jacobi A. (2009), A review on polymer heat exchangers for HVAC\&R applications, International Journal of Refrigeration, vol.32, pp. 763-779.

Torquato S. \& Rintoul M.D. (1995), Effect of interface on the properties of composite media, Physical Review Letters, vol.75, pp. 4067-4070.

Tritt T.M. \& Weston D. (2004), Measurement techniques and considerations for determining thermal conductivity of bulk materials. Tritt T.M., Thermal conductivity theory, properties, and applications, Kluwer Academic/Plenum Publishers, New York, pp. 187-203.

Tu H. \& Ye L. (2009), Thermal conductive PS/graphite composites, Polymer Advanced Technology, vol.20, pp. 21-27.

Vakili M.H.; Ebadi-Dehaghani H.; Haghshenas-Fard M. (2011), Crystallization and Thermal Conductivity of $\mathrm{CaCO}_{3}$ Nanoparticle Filled Polypropylene. Journal of Macromolocular Science: Part B. Physics, vol.50, pp.1637-1645.

Veca M.L.; Meziani M.J.; Wang W.; Wang X.; Lu F.; Zhang P.; Lin Y., Fee R.; Connell J.W. \& Sun Y. (2009), Carbon nanosheets for polymeric nanocomposites with high thermal conductivity, Advanced Material, vol. 21, pp. 2088-2092.

Wang J.; Carson J.K.; North M.F. \& Cleland D.J. (2008), A new structural model of effective thermal conductivity for heterogeneous materials with cocontinuous phases, International Journal of Heat and Mass Transfer, vol.51, pp. 2389-2397.

Weidenfeller B.; Hofer M \& Schilling F. R. (2004), Thermal conductivity, thermal diffusivity, and specific heat capacity of particle filled polypropylene. Composites: Part A, vol.35, pp. 423-429. 
Wolff S. \& Wang M.J. (1993), Carbon black science \& technology (2nd ed.), Marcel Dekker, New York.

Wong Y.W.; Lo K.L. \& Shin F.G. (2001), Electrical and thermal properties of composite of liquid crystalline polymer filled with carbon black, Journal of Applied Polymer Science, vol.82, pp. 1549-1555.

Wypych G. (2000), Handbook of fillers: physical properties of fillers and filled materials, ChemTec Publishing, Toronto.

Yano O. \& Yamaoka H. (1995), Cryogenic properties of polymers, Progress Polymer Science, vol.20, pp. 585-613.

Ye C.M.; Shentu B.Q. \& Weng Z.X. (2006), Thermal conductivity of high density polyethylene filled with graphite, Journal of Applied Polymer Science, vol.101, pp. 3806-3810.

Yu S.; Hing P. \& Hu X. (2002), Thermal conductivity of polystyrene-aluminum nitride composite, Composites: Part A, vol.33, pp. 289-292.

Zhang X.; Fujiwara S. \& Fujii M. (2000), Measurements of thermal conductivity and electrical conductivity of a single carbon fiber, International Journal of Thermophysics, vol.21, pp. 965-980.

Zhao H. \& Li R.K.Y. (2006), A study on the photo-degradation of zinc oxide (ZnO) filled polypropylene nanocomposites. Polymer; vol.47, pp.3207-3217.

Zeng J.; Fu R.; Agathopoulos S.; Zhang S.; Song X. \& He H. (2009), Numerical simulation of thermal conductivity of particle filled epoxy composites, Journal of Electronic Packaging, vol.131, pp.1-7.

Zhi C.; Bando Y.; Terao T.; Tang C.; Kuwahara H. \& Golberg D. (2009), Towards thermoconductive, electrically insulating polymeric composites with boron nitride nanotubes as fillers, Advanced Functional Materials, vol.19, pp. 1857-1862.

Zhong C.; Yang Q. \& Wang W. (2001), Correlation and prediction of the thermal conductivity of amorphous polymers, Fluid Phase Equilibria, vol.181, pp. 195-202.

Zhou H.; Zhang S. \& Yang M. (2007), The effect of heat-transfer passages on the effective thermal conductivity of high filler loading composite materials, Composites Science and Technology, vol.67, pp. 1035-1040.

Zhou W.; Qi S.; An Q.; Zhao H. \& Liu N. (2007), Thermal conductivity of boron nitride reinforced polyethylene composites, Materials Research Bulletin, vol.42, pp. 18631873. 


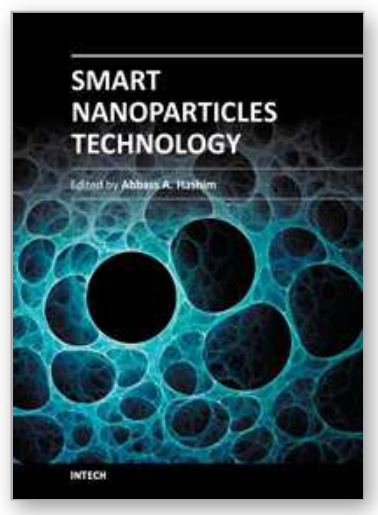

\author{
Smart Nanoparticles Technology \\ Edited by Dr. Abbass Hashim
}

ISBN 978-953-51-0500-8

Hard cover, 576 pages

Publisher InTech

Published online 18, April, 2012

Published in print edition April, 2012

In the last few years, Nanoparticles and their applications dramatically diverted science in the direction of brand new philosophy. The properties of many conventional materials changed when formed from nanoparticles. Nanoparticles have a greater surface area per weight than larger particles which causes them to be more reactive and effective than other molecules. In this book, we (InTech publisher, editor and authors) have invested a lot of effort to include 25 most advanced technology chapters. The book is organised into three well-heeled parts. We would like to invite all Nanotechnology scientists to read and share the knowledge and contents of this book.

\title{
How to reference
}

In order to correctly reference this scholarly work, feel free to copy and paste the following:

Hassan Ebadi-Dehaghani and Monireh Nazempour (2012). Thermal Conductivity of Nanoparticles Filled Polymers, Smart Nanoparticles Technology, Dr. Abbass Hashim (Ed.), ISBN: 978-953-51-0500-8, InTech, Available from: http://www.intechopen.com/books/smart-nanoparticles-technology/thermal-conductivity-ofnanoparticles-filled-polymers-

\section{INTECH}

open science | open minds

\section{InTech Europe}

University Campus STeP Ri

Slavka Krautzeka 83/A

51000 Rijeka, Croatia

Phone: +385 (51) 770447

Fax: +385 (51) 686166

www.intechopen.com

\section{InTech China}

Unit 405, Office Block, Hotel Equatorial Shanghai

No.65, Yan An Road (West), Shanghai, 200040, China 中国上海市延安西路65号上海国际贵都大饭店办公楼 405 单元

Phone: $+86-21-62489820$

Fax: +86-21-62489821 
(C) 2012 The Author(s). Licensee IntechOpen. This is an open access article distributed under the terms of the Creative Commons Attribution 3.0 License, which permits unrestricted use, distribution, and reproduction in any medium, provided the original work is properly cited. 